\title{
PENERAPAN METODE PROMETHEE DENGAN ENTROPY DALAM PENGAMBILAN KEPUTUSAN UNTUK MENENTUKAN SISWA BERPRESTASI
}

\author{
Abdul Hamid Majdi \\ Program Studi Teknik Informatika, STMIK Bumigora Mataram \\ Email : abdulhamidmajdi@yahoo.co.id
}

\begin{abstract}
Abstrak
Mewujudkan sekolah yang berkompetitif, bermutu dan berprestasi merupakan salah satu bentuk misi dan visi yang di terapkan dalam sekolah terutama dalam pribadi siswa. Untuk mewujudkan keinginan itu setiap sekolah perlu mengevaluasi, meningkatkan lebih lanjut lagi pelayanannya baik mengenai teknik pengajaran, penilaian, penjaminan mutu agar menjadikan sekolah yang berkompetitif, bermutu dan berprestasi. Dalam hal ini wali kelas dihadapkan suatu masalah penilaian kualitas tiap siswa sesuai dengan kriteria yang diinginkan sekolah. dan menjadi beban wali kelas karena banyaknya pilihan dalam menentukan mana yang lebih berprioritas dan harus dibandingkan sehingga tidak bisa tepat waktu dalam penyelesaian nya. Untuk mengidentifikasi masalah yang dihadapi pihak sekolah terutama wali kelas di gunakan adalah pendekatan promethee yang merupakan salah satu metode penentuan urutan atau prioritas dalam analisis multikriteria sangat tepat untuk digunakan karena dugaan dari dominasi kriteria yang digunakan dalam promethee adalah penggunaan nilai dalam hubungan outrangking. Sehingga diperoleh solusi atau hasil dari beberapa alternatif untuk diambil sebuah keputusan. Hasil perangkingan menunjukkan bahwa promethee I yang berdasarkan pada nilai leaving flow dan entering flow sedangkan Promethee II yang didasarkan pada nilai net flow.
\end{abstract}

Kata Kunci : Multikriteria, Sistem Pendukung Keputusan, Entropy, Promethee.

\begin{abstract}
Realizing competitiveness, quality and achievement schools is one of the forms of mission and vision that is applied in schools, especially in students. To realize that desire every school needs to evaluate, further improve its services both on teaching techniques, assessment, and quality assurance in order to make schools that are competitive, quality and achievers. In this case the homeroom is confronted with a problem of the quality assessment of each student according to the criteria desired by the school, and become the burden of the homeroom because of the many choices in determining which ones are more prioritized and must be compared so that they cannot be timely in their completion. To identify the problems faced by the school, especially the homeroom teacher is used is a promethee approach which is one method of determining the order or priority in multicriteria analysis is very appropriate to use because the assumption of the dominance of the criteria used in promethee is the use of values in outrangking relationships. So that a solution or result of several alternatives is obtained to make a decision. The results of the ranking show that promethee I is based on the value of leaving flow and entering flow while Promethee II is based on the net flow value.
\end{abstract}

Keyword: Multicriteria, Decision Support System, Entropy, Promethee.

\section{PENDAHULUAN}

Setiap lembaga pendidikan khususnya pada sekolah menengah kejuruan (SMK) selalu memiliki visi dan misi yang berorientasi pada lulusan yang cerdas, unggul dalam prestasi, berwawasan luas dan mewujudkan peringkat penilaian bertaraf internasional. Untuk mewujudkan keinginan itu setiap sekolah perlu mengevaluasi, meningkatkan lebih lanjut lagi 
pelayanannya baik mengenai pengajaran, penilaian, penjaminan mutu agar menjadikan sekolah yang berkompetitif, bermutu dan berprestasi.

Dengan adanya hal itu, wali kelas dihadapkan suatu masalah pada penilaian kualitas tiap siswa sesuai dengan kriteria yang diinginkan sekolah. Hal ini menjadikan beban wali kelas karena banyaknya pilihan dalam menentukan mana yang lebih berprioritas dan harus dibandingkan sehingga tidak bisa tepat waktu dalam penyelesaiannya. Untuk penilaian disini wali kelas menghitung dan menentukan sendiri ranking 1 sampai 10 baik untuk kelas $\mathrm{X}$ s/d XII yang terdiri dari 36 siswa per kelas dengan melihat beberapa kriteria yaitu: mengumpulkan data presensi, tingkah laku, kegiatan ektrakulikuler dan nilai raport yang didapat dari nilai harian, nilai ujian tengah semester dan nilai akhir semester. Setiap pembagian raport pihak sekolah selalu memberikan penghargaan terhadap siswa-siswi yang mendapatkan prestasi. Maka dari itu wali kelas dituntut untuk menentukan siswa-siswi yang layak mendapatkan prestasi berdasarkan beberapa kriteria yang sudah ditentukan di sekolah seperti data presensi, data perilaku, kegiatan ekstrakulikuler, dan nilai rapor.

Penentuan siswa tersebut diatas dapat dikategorikan sebagai kasus multikriteria karena terdapat beberapa faktor yang menimbulkan berbagai pilihan dengan nilai-nilai yang berbeda, sehingga diperlukan suatu teknologi penentuan prestasi siswa untuk membantu wali kelas mengelola penilaian prestasi siswa agar dapat mengambil keputusan dengan tepat yaitu dengan penerapan metode promethee dan entropy. Pada penelitian ini bertujuan untuk merancang dan membangun sistem pendukung keputusan untuk menentukan siswa berprestasi pada SMKN 1 Batukliang dengan menerapkan metode Promethee dan Entropy.

\section{TINJAUAN PUSTAKA}

Pada awalnya Turban \& Aronson (2005), mendefinisikan sistem pendukung keputusan sebagai sistem yang digunakan untuk mendukung dan membantu pihak manajemen melakukan pengambilan keputusan pada kondisi semi terstruktur dan tidak terstruktur. Pada dasarnya konsep SPK hanyalah sebatas pada kegiatan membantu para manajer melakukan penilaian serta menggantikan posisi dan peran manajer.

Konsep SPK pertama kali diperkenalkan pada awal tahun 1970-an oleh Michael Scott Morton, yang selanjutnya dikenal dengan istilah “Management Decision System”. Konsep SPK merupakan sebuah sistem interaktif berbasis komputer yang membantu pembuatan keputusan memanfaatkan data dan model untuk menyelesaiakn masalah-masalah yang bersifat tidak terstruktur dan semi terstruktur. SPK dirancang untuk menunjang seluruh tahapan pembuatan keputusan, yang dimulai dari tahapan mengidentifikasi masalah, memilih data yang relevan, menentukan pendekatan yang digunakan dalam proses pembuatan keputusan sampai pada kegiatan mengevaluasi pemilihan alternatif.

Metode Entropy dapat digunakan untuk menentukan suatu bobot. Entropy menyelidiki keserasian dalam diskriminasi diantara sekumpulan data. Sekumpulan data nilai alternatif pada kriteria tertentu digambarkan dalam Decision matrix (DM). Menggunakan metode entropi, kriteria dengan variasi nilai tertinggi akan mendapatkan bobot tertinggi. Langkahlangkah yang digunakan dalam metode ini adalah sebagai berikut :

1. Membuat tabel data kriteria

Kriteria yang diidentifikasi bisa berupa kriteria kualitatif maupun kuantitatif, namun semuanya harus bisa terukur. Satuan tiap kriteria boleh berbeda-beda.

2. Normalisasi tabel data kriteria

Rumus normalisasi adalah sebagai berikut 


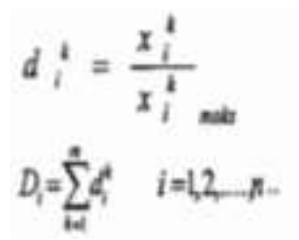

Dimana :

$\mathbf{d}_{\mathbf{k}}^{\mathbf{i}} \quad=$ nilai data yang telah dinormaliasasi.

$\mathbf{x}_{\mathbf{k}}^{\mathbf{i}} \quad$ = nilai data yang belum dinormalisasi.

$\mathbf{X}_{\mathbf{k}}^{\mathbf{i}} \mathbf{k}=$ nilai data yang belum dinormalisasi yang mempunyai nilai paling tinggi

$\mathbf{D}_{\mathbf{i}}=$ jumlah nilai data yang telah dinormalisasi.

3. Perhitungan Entropy

Langkah selanjutnya adalah pengukuran Entropy untuk setiap atribut ke-i. rumusnya adalah :

$$
\begin{aligned}
& e_{\operatorname{man}}=\ln m \\
& K=\frac{1}{e_{r=0}} \\
& e\left(d_{i}\right)=-K \sum_{i=1}^{*} \frac{d_{i}^{*}}{D_{i}} \ln \frac{d_{i}^{*}}{D_{i}}, \quad K>0
\end{aligned}
$$

Dimana $: m=$ jumlah alternatif

Setelah mendapatkan $e\left(d_{i}\right)$ untuk masing-masing atribut, maka dapat ditentukan total Entropy untuk masing-masing atribut, rumusnya adalah :

$$
E=\sum_{i=1}^{n} e\left(d_{i}\right)
$$

4. Perhitungan Bobot Entropy

Langkah berikutnya adalah menghitung bobot dengan menggunakan rumus sebagai berikut :

$$
\begin{aligned}
& \overline{\lambda_{1}}=\frac{1}{n-E}\left[1-e\left(d_{j}\right)\right], 0 \leq \sum_{i} \leq 1 \\
& \sum_{i=1}^{n} \bar{\lambda}_{3}= \pm 1
\end{aligned}
$$

5. Setelah mendapatkan bobot Entropy untuk masing-masing kriteria jika sebelumnya telah ada bobot awal atau bobot yang telah ditentukan sebelumnya maka hasil bobot Entropy yang sebenarnya untuk tiap kriteria akan didapat dengan perhitungan berikut ini :

$$
\lambda_{i}=\frac{\overline{\lambda_{1}} \times w,}{\sum_{i=1}^{*} \overline{\lambda_{i} \times w}}
$$

Promethee adalah salah satu metode penentuan urutan atau prioritas dalam analisis multikriteria atau MCDM (Multi Criterion Decision Making). Semua parameter yang dinyatakan mempunyai pengaruh nyata menurut pandangan ekonomi. Dalam metode promethee ada enam bentuk fungsi preferensi kriteria. Untuk memberikan gambaran yang lebih baik terhadap area yang tidak sama, maka digunakan tipe fungsi preferensi. Ke enam tipe preferensi tersebut meliputi:

1. Tipe Biasa (Usual Criterion)

Tipe Usual adalah tipe dasar, yang tidak memiliki nilai threshold atau kecenderungan dan tipe ini jarang digunakan. Pada tipe ini dianggap tidak ada beda antara alternatif $a$ dan alternatif $b$ jika $a=b$ atau $f(a)=f(b)$, maka nilai preferensinya bernilai 0 (Nol) atau $p(x)=0$. Apabila nilai kriteria pada masing-masing alternatif memiliki nilai berbeda, maka pembuat 
keputusan membuat preferensi mutlak bernilai 1 (Satu) atau $P(x)=1$ untuk alternatif yang memiliki nilai lebih baik. Fungsi $P(x)$ untuk preferensi ini disajikan sebagai berikut :

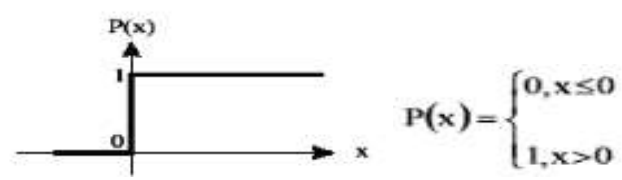

2. Tipe Quasi (Quasi Criterion atau $U$-Shape)

Tipe Quasi sering digunakan dalam penilaian suatu data dari segi kualitas atau mutu, yang mana tipe ini menggunakan satu threshold atau kecendrungan yang sudah ditentukan, dalam kasus ini threshold itu adalah indifference. Indifference ini biasnya dilambangkan dengan karakter $m$ atau $q$, dan nilai indifference harus diatas 0 (Nol). Suatu alternatif memiliki nilai preferensi yang sama penting selama selisih atau nilai $P(x)$ dari masingmasing alternatif tidak melebihi nilai threshold. Apabila selisih hasil evaluasi untuk masing-masing alternatif melebihi nilai $m$ maka terjadi bentuk preferensi mutlak, jika pembuat memutuskan menggunakan kriteria ini, maka decision maker tersebut harus menentukan nilai $m$, dimana nilai ini dapat dijelaskan pengaruh yang signifikan dari suatu kriteria. Fungsi $P(x)$ untuk preferensi ini disajikan sebagai berikut:

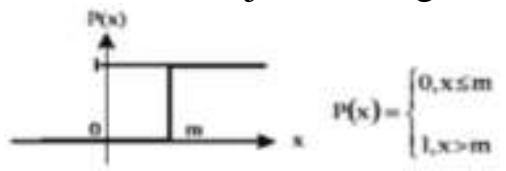

3. Tipe Linier (Liniear Criterion atau V-Shape)

Tipe Linier acapkali digunakan dalam penilaian dari segi kuantitatif atau banyaknya jumlah, yang mana tipe ini menggunakan satu threshold atau kecendrungan yang sudah ditentukan, dalam kasus ini threshold itu adalah preference. Preference ini biasanya dilambangkan dengan karakter $n$ atau $p$, dan nilai preference harus diatas 0 (Nol). Kriteria ini menjelaskan bahwa selama nilai selisih memiliki yang lebih rendah dari $n$, maka nilai preferensi dari pembuat keputusan meningkat secara linier dengan nilai $x$ jika nilai $x$ lebih besar dibandingkan dengan nillai $n$, maka terjadi preferensi mutlak. Fungsi $P(x)$ untuk preferensi ini disajikan sebagai berikut :

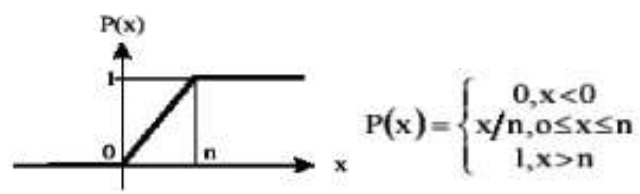

4. Tipe Tingkatan (Level Criterion)

Tipe ini mirip dengan tipe Quasi yang sering digunakan dalam penilaian suatu data dari segi kualitas atau mutu. Tipe ini juga menggunakan threshold indifference $(m)$ tetapi ditambahkan satu threshold lagi yaitu preference (n). Nilai indifference serta preference harus diatas $0(\mathrm{Nol})$ dan nilai indifference harus di bawah nilai preference. Apabila alternatif tidak memiliki perbedaan $(x)$, maka nilai preferensi sama dengan 0 (Nol) atau $P(x)=0$. Jika $x$ berada diatas nilai $m$ dan dibawah nilai $n$, hal ini berarti situasi preferensi yang lemah $P(x)=0.5$. dan jika $x$ lebih besar atau sama dengan nilai $n$ maka terjadi preferensi mutlak $P(x)=1$. Fungsi $P(x)$ untuk preferensi ini disajikan sebagai berikut :

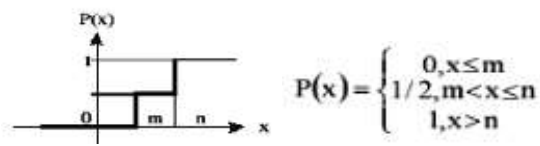

5. Tipe Linear Quasi (Linear Criterion with indifference) 
Tipe Linear Quasi juga mirip dengan tipe Linear yang acapkali digunakan dalam penilaian dari segi kuantitatif atau banyaknya jumlah. Tipe ini juga menggunakan threshold preference $(n)$ tetapi ditambahkan satu threshold lagi yaitu indefference $(m)$. Nilai indifference serta preference harus diatas 0 (Nol) dan nilai indifference harus di bawah nilai preference. Pengambilan keputusan mempertimbangkan peningkatan preferensi secara linier dari tidak berbeda hingga preferensi mutlak dalam area antara dua kecenderungan $m$ dan $n$. Fungsi $P(x)$ untuk preferensi ini disajikan sebagai berikut :

6. Tipe Gaussian

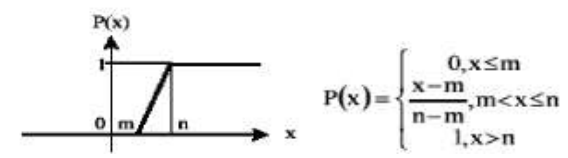

Tipe Gaussian sering digunakan untuk mencari nilai aman atau titik aman pada data yang bersifat continue atau berjalan terus. Tipe ini memiliki nilai threshold yaitu Gaussian threshold $(\sigma)$ yang berhubungan dengan nilai standar deviasi atau distribusi normal dalam statistik. Fungsi $P(x)$ untuk preferensi ini disajikan p sebagai berikut :

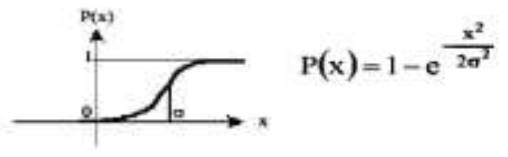

\section{METODE}

Dalam melakukan penelitian ini, metode pengembangan sistem yang penulis gunakan adalah metode waterfall. Metode waterfall mempunyai beberapa tahapan yaitu tahap analisis kebutuhan, tahap desain sistem, tahap implementasi (pembangunan sistem), tahap pengujian, dan tahap penerapan \& pemeliharaan (Simarmata, 2010). Akan tetapi, tahap-tahap yang penulis lakukan dalam skripsi ini hanya sampai pada tahap pengujian saja. Penjelasan mengenai tahap-tahap tersebut antara lain: (1) Analisis Kebutuhan: Setelah pengumpulan informasi mengenai hal-hal yang berkaitan dengan siswa berprestasi, kegiatan selanjutnya yaitu melakukan analisis terhadap kebutuhan system, (2) Desain Sistem: Merancang sistem yang akan dibangun berdasarkan data yang dihasilkan pada tahap analisis untuk melakukan tahapan proses selanjutnya, yang meliputi normalisasi, Model Entity Relationship Diagram (ERD) dan Data Flow Diagram (DFD) berfungsi mempermudah pihak sekolah melihat rancangan yang akan dibangun guna dapat menganalisis kesalahan pada rancangan dan memperbaiki rancangan, (3) Implementasi: Implementasi merupakan tahap penerjemah desain sistem ke dalam bahasa yang dapat dikenali oleh komputer. Pada tahap inilah wujud sistem alternatif yang dibuat akan terlihat secara nyata dalam bentuk aplikasi komputer, (4) Pengujian: Pada tahapan ini adalah melakukan pengujian dari program atau aplikasi yang dihasilkan dengan maksud untuk mengetahui siswa yang layak mendapatkan prestasi pada kelas X s/d XII.

\section{HASIL DAN PEMBAHASAN}

\section{Analisis dan Perancangan Sistem}

Identifikasi Masalah

Adapun masalah yang dihadapi pada pihak sekolah terutama pada bagian siswa untuk menentukan siswa yang berhak mendapatkan prestasi tinggi yaitu (a) Wali kelas kesulitan menentukan penilaian kualitas tiap siswa sesuai dengan kriteria yang diinginkan sekolah, (b) Wali kelas kesulitan karena banyaknya pilihan dalam menentukan mana yang lebih 
berprioritas dan harus dibandingkan sehingga tidak bisa tepat waktu dalam penyelesaiannya. Sementara itu, penyebab permasalahan yang timbul dari masalah yang sudah diuraikan tadi yaitu: (a) Terlalu banyak kriteria yang dinilai, sehingga proses penilaian tidak selesai tepat pada waktunya, (b) Proses pemilihan siswa berprestasi masih menggunakan cara lama yaitu dinilai dengan cara manual. Selanjutnya, analisis alternatif solusi masalah adalah yaitu merancang dan membangun Sistem Pendukung Keputusan untuk menentukan siswa berprestasi dengan menerapkan metode promethee dan entropy.

\section{Entity Relationship Diagram (ERD)}

ERD merupakan model konseptual yang mendeskripsikan hubungan antara penyimpanan data dalam diagram arus data yang digunakan untuk memodelkan struktur data dan hubungan antara data (leman, 1998). Berikut gambaran ERD yang dibuat :

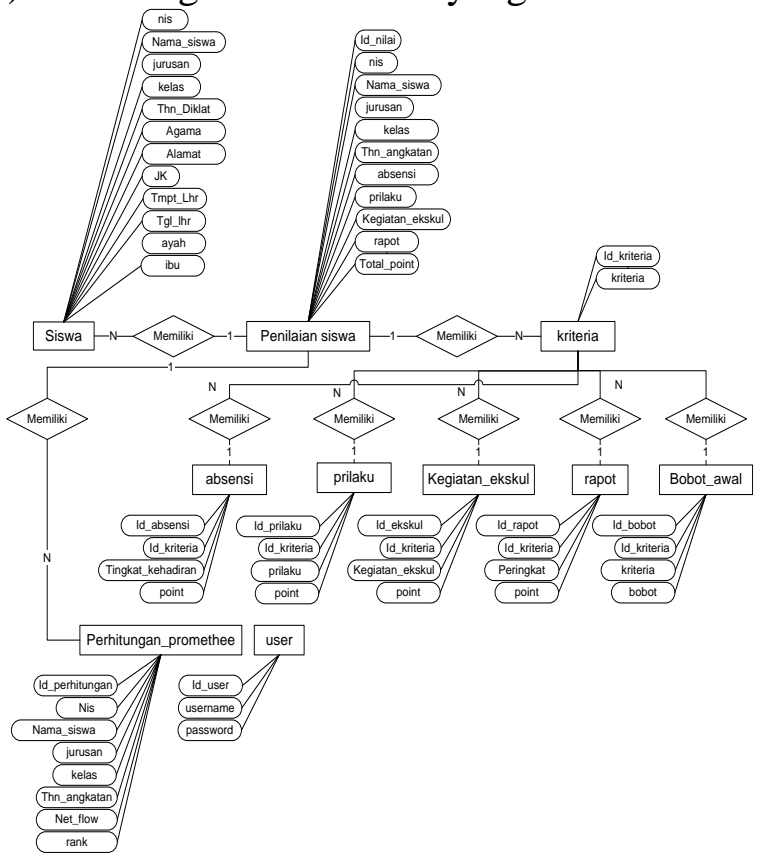

Gambar 1. ERD Sistem Pendukung Keputusan Pemilihan Siswa Berprestasi

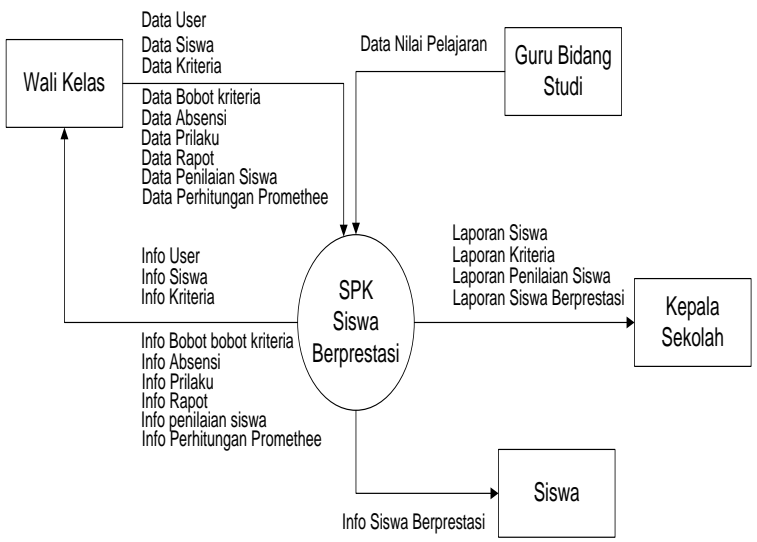

Gambar 2. Diagram Konteks Sistem Pendukung Keputusan 

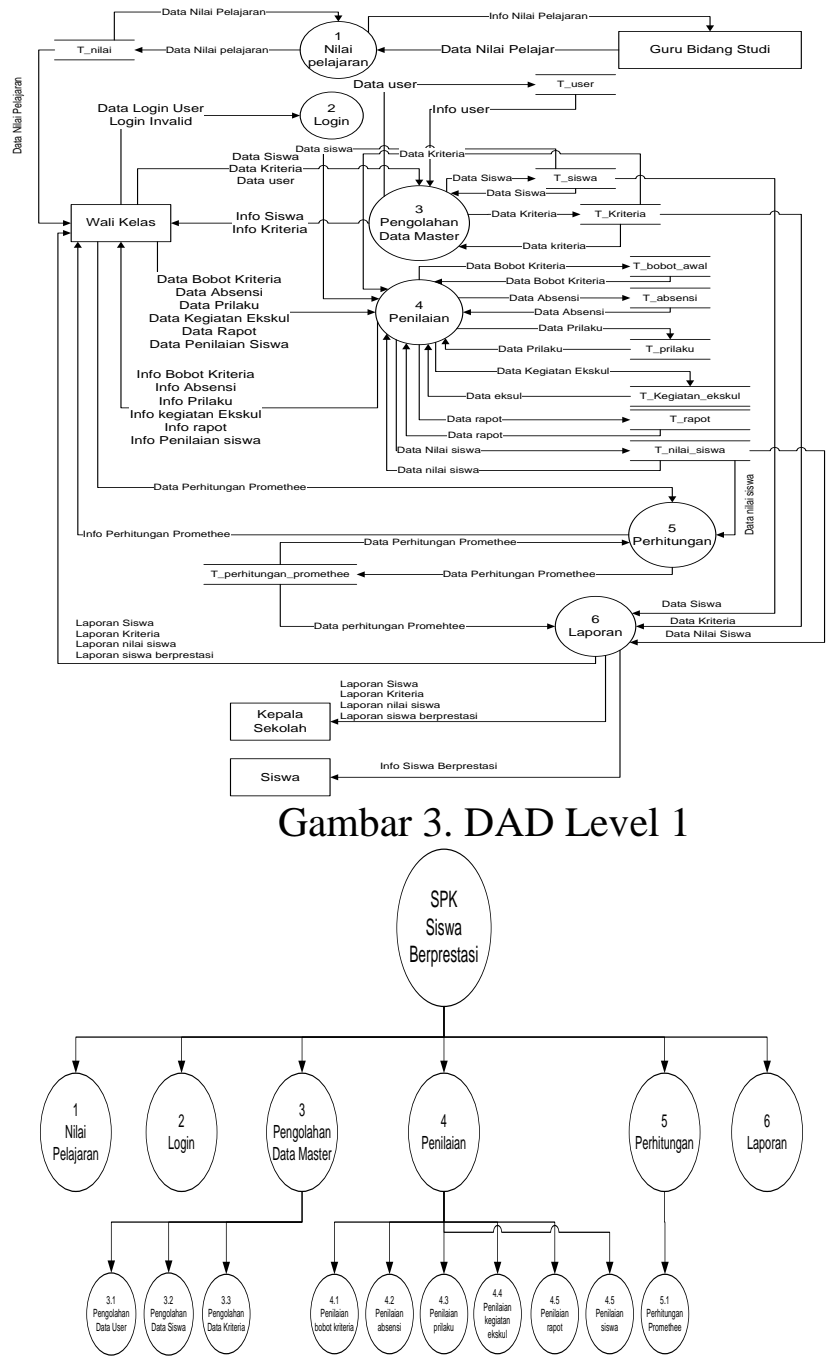

Gambar 4. Bagan Berjenjang

\section{Implementasi}

\section{Persiapan Implementasi}

Tahapan yang dilakukan pada proses ini adalah: (1) Instalasi DBMS MySQL Versi 5.1 digunakan untuk pembuatan database sistem pendukung keputusan, (2) Instalasi MySQL (3) Instalasi Borland Delphi 7.0 untuk pembuatan aplikasi sistem pendukung keputusan, (4) Instalasi Report Builder digunakan untuk pembuatan laporan.

\section{Penjelasan Program}

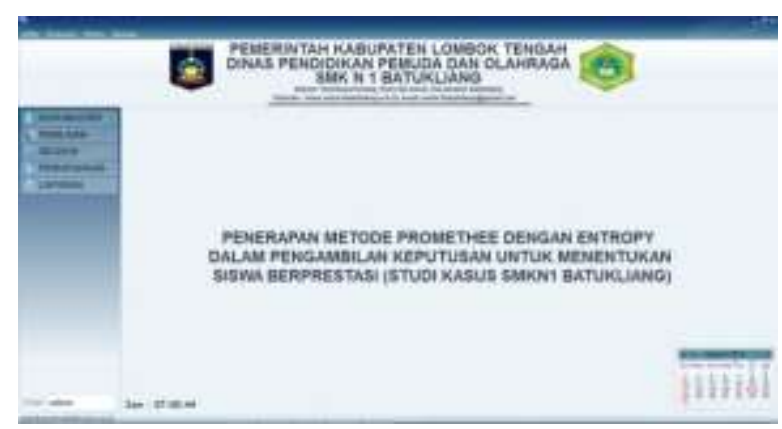

Gambar 5. Form Menu Utama 
Volume 1, Nomor 2, Desember 2017

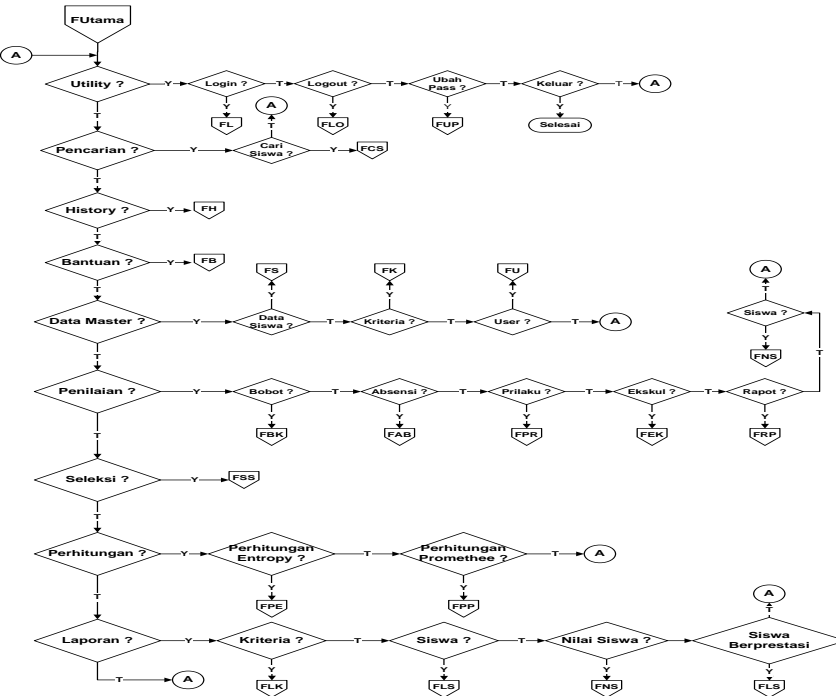

Gambar 6. Flowchart Menu Utama

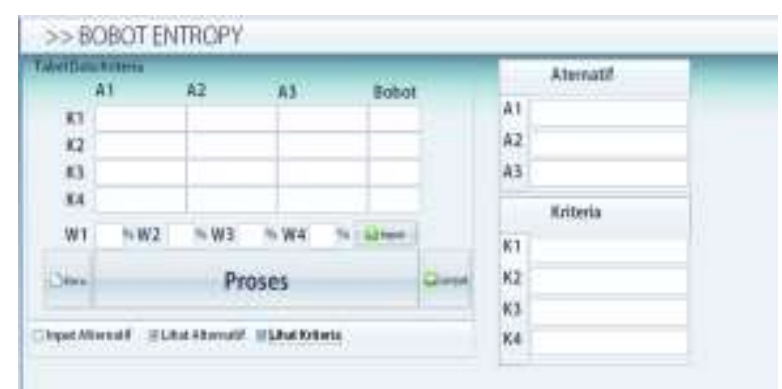

Gambar 7. Form Perhitungan Entropy

\begin{tabular}{|c|c|c|c|}
\hline Kriteria & Bobot & \multicolumn{2}{|c|}{ Kaidah } \\
\hline Absensi & & Max & - \\
\hline Prilaku & & Max & - \\
\hline Kegiatan Ektrakulikuler & & Max & 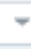 \\
\hline Rapot & & Max & $\rightarrow$ \\
\hline
\end{tabular}

Gambar 8. Form Perhitungan Promethee (Kaidah)

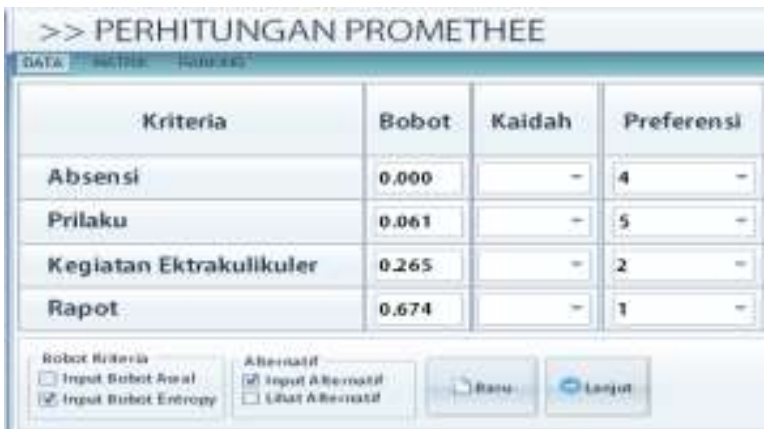

Gambar 9. Form Perhitungan Promethee(Preferensi)

EDUMATIC: Jurnal Pendidikan Informatika | 62 
Volume 1, Nomor 2, Desember 2017

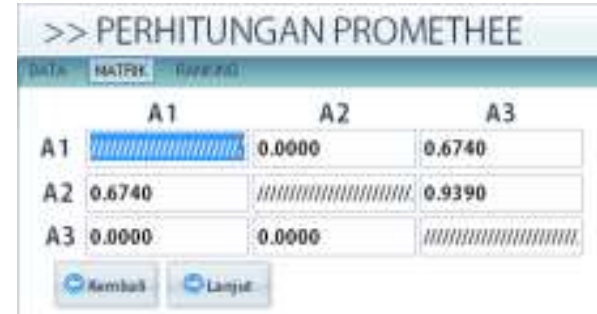

Gambar 10. Form Perhitungan Promethee(Matriks)

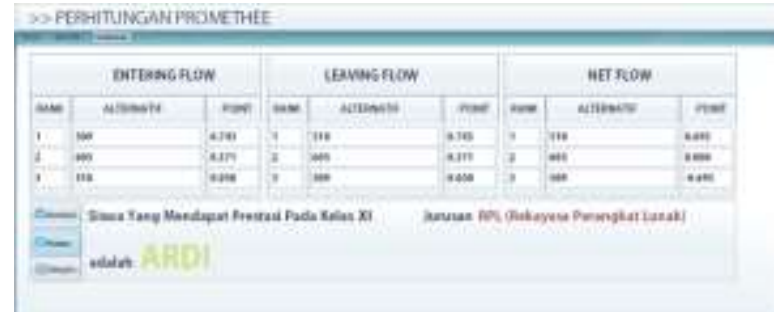

Gambar 11. Form Perhitungan Promethee (Perangkingan)

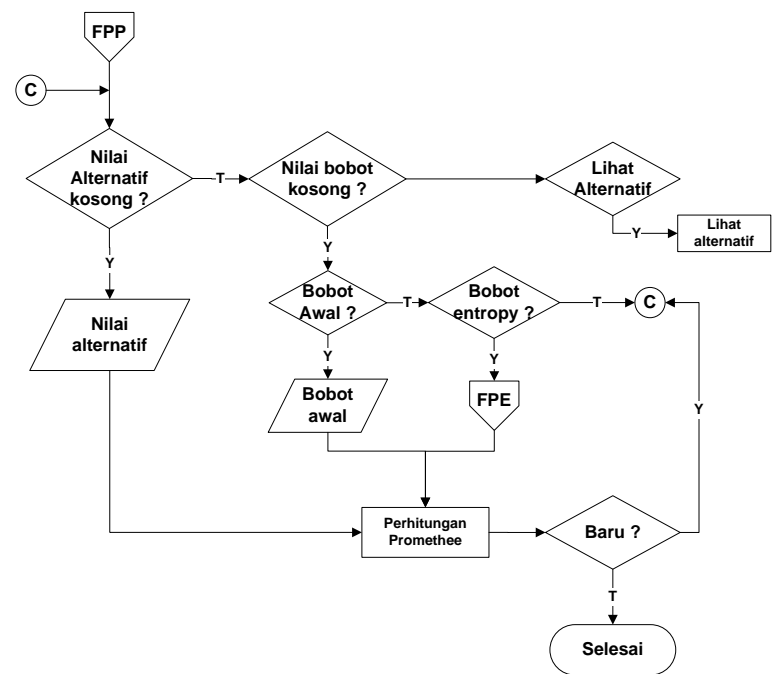

Gambar 12. Flowchart Perhitungan Promethee

Ujicoba Program

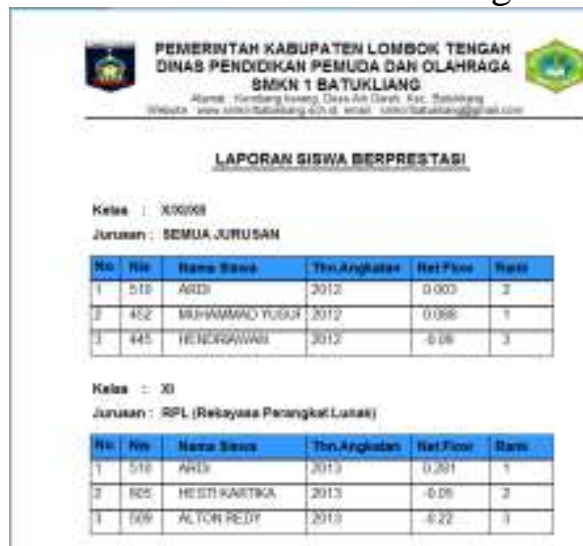

Gambar 13. Laporan Siswa Berprestasi

EDUMATIC: Jurnal Pendidikan Informatika | 63 
Ujicoba yang dilakukan penulis dengan cara membagikan kuesioner ke beberapa pihak sekolah terutama wali kelas. Dalam tahap ujicoba sistem ini penulis mengambil sebanyak 8 responden diantaranya adalah : ujicoba pemakaian program sistem pendukung keputusan yang dilakukan wali kelas.

\section{SIMPULAN}

Berdasarkan hasil analisis dan pembahasan di atas, maka simpulan pada penelitian ini adalalah: (1) Aplikasi yang dibuat membantu pihak sekolah terutama wali kelas dalam menentukan siswa yang layak mendapatkan prestasi, (2) Metode entropy digunakan karena membantu pengambil keputusan dalam menghasilkan bobot baru pada masing-masing kriteria, (3) Kriteria dengan variasi nilai tertinggi akan mendapatkan bobot tertinggi, (4) Promethee dapat digunakan untuk penentuan urutan (prioritas) dalam analisis multikriteria (kasus : pemilihan siswa berprestasi) untuk 3 alternatif.

\section{REFERENSI}

Brans JP and Vincke P. (1985) A Preference Ranking Organization Method: The PROMETHEE method for MCDM. Management Science. 31, 6: 647-656.

Brans, J.P., Vinckle and B. Mareschal. (1986). How to Select and How to Rank Projects; The Promethee method. European Jounal of Operational research, Elsevier Science Publisher B.V., Holland. P.228-238.

HM, Jogiyanto. (2005). Analisis \& Desai Sistem Informasi. Yogyakarta, Andi Offset.

Kadir, Abdul. (2006). Dasar Aplikasi Database MySQL Dlphi. Yogyakarta : CV. Andi Offset.

Leman., (1998). Metodologi Pengembangan Sistem Informasi. Jakarta: PT. Elekmedia Komputindo Kelompok Gramedia.

Mcleod, R. dan G.Schell. (2004). Sistem Informasi Manajemen Edisi Kedelapan Bahasa Indonesia. Jakarta: PT. Indeks.

Novaliendry D. (2005). Sistem Pendukung Keputusan Penentuan Media Promosi Menggunakan Metode Promethee (Studi Kasus Pada STMIK Indonesia di Padang). Tesis. Yogyakarta: S2 Ilkom FMIPA UGM.

Simarmata, Janner.(2010). Rekayasa Perangkat Lunak. Yogyakarta, Andi Offset.

Turban E, Ting-Peng Liang, Jay E. Aronson. (2005). Decision Support Systems and intelligent system $\left(7^{\text {th }}\right.$ Ed.) (Dwi Prabantini, Trans.) Yogyakarta, Andi 